\title{
Optimal Control Strategy of Companies: Inheriting Period and Carbon Emission Reduction
}

\author{
Jin Liang and Wenlin Huang (iD \\ School of Mathematical Sciences, Tongji University, Shanghai 200092, China \\ Correspondence should be addressed to Wenlin Huang; hwl_19961029@tongji.edu.cn
}

Received 28 May 2020; Revised 4 October 2020; Accepted 19 October 2020; Published 4 November 2020

Academic Editor: Mohammad D. Aliyu

Copyright (C) 2020 Jin Liang and Wenlin Huang. This is an open access article distributed under the Creative Commons Attribution License, which permits unrestricted use, distribution, and reproduction in any medium, provided the original work is properly cited.

\begin{abstract}
In this paper, we develop an optimal control model of companies for the inheriting period, during which interphase banking and borrowing of allowances are allowable. By considering the emission reduction policy and the initial auction amount, we optimize the problem in two steps. The model is then converted into a two-dimensional Hamilton-Jacobi-Bellman equation. The numerical results, analysis, and comparisons are presented. Finally, we highlight several policy implications from the perspectives of companies and governments.
\end{abstract}

\section{Introduction}

With global warming, more and more people are becoming aware of the importance of controlling greenhouse gas emissions and protecting the environment. Countries are paying greater attention to energy conservation and emission reduction. The Kyoto Protocol, adopted in 1997, imposes mandatory emission caps on signatories. In addition, countries set emission caps for emission reduction companies (called "regulated entities"). Countries or companies can purchase or sell emission rights to achieve prescribed emission standards, resulting in a bilateral transaction called "carbon trading." This has led to the rise and boom of the carbon market, which has become an important part of the world's policy to address climate change. The carbon market will play a key role in the transition to a low-carbon economy. According to International Carbon Action Partnership (ICAP)'s Emissions Trading Worldwide: Status Report 2019 [1], there are currently 20 carbon trading systems in operation worldwide, covering 27 jurisdictions. Six other jurisdictions are planning to launch carbon trading systems in the coming years, including China and Mexico. In addition, 12 different levels of government have begun to consider establishing carbon markets as an important part of their climate policies, including Chile, Thailand, and Vietnam.
The European Union Emissions Trading System (EU ETS) [2], the world's largest carbon trading market, belongs to the cap-and-trade program. This means that the emissions of a regulated entity must not exceed the cap set by the country. Otherwise, they will need to pay penalties or purchase allowances in the market. The allocation of emission allowances takes into account factors such as historical emissions, predicted emissions, and emission standards of companies. In order to avoid a situation whereby specific industries would make huge profits due to free distribution and place companies that take early abatement actions in a competitive position, the allocation method in the EU ETS has gradually transitioned from "free allocation mainly, auction allocation supplemented" to "auction allocation mainly, free allocation supplemented" [3]. For example, in the power industry of the EU ETS, the government auctioned at most $5 \%$ of allowances in the first phase and reached $10 \%$ in the second phase. After 2020, the auctioning rate may reach $100 \%$ across Europe $[4,5]$. In 2008, the Regional Greenhouse Gas Initiative (RGGI) required that at least $25 \%$ of allowances were allocated to power producers in 10 northeastern states of the United States through auctions [4]. Therefore, it is important for companies to choose auction amounts of allowances to achieve abatement targets and minimize the total cost. Guo 
[6] subsequently developed an optimal control model for companies' emission reduction and purchasing strategies during a single trading period. Using a two-step method, Guo formulated the balance of allowance purchases and carbon reduction equilibrium equation. In the second phase of the EU ETS, due to the unexpected financial crisis, the European economic contraction resulted in a significant reduction in carbon emissions, which reduced the demand for emission permits, and the prices continued to fall. In order to prevent the carbon market price from returning to zero at the end of the second phase (end of 2012), the EU ETS allowed unused permits in the second phase to be used in the third phase, that is, to allow interphase banking of permits. As a result, many companies bought permits on dips at the end of 2012, thus supporting the carbon market price [3]. Moreover, the banking mechanism can motivate companies to commence energy conservation and emission reduction actions as early as possible [7]. Furthermore, Guo [6] considered the case of two trading periods, in which interphase banking is allowable. In fact, another flexible intertemporal mechanism in carbon trading is borrowing, which means that companies can borrow permits from future allocations for use in the current period and adjust permits in a relatively long period of time. This also prompts companies to formulate longer-term energy saving and emission reduction plans $[8,9]$. So far, these flexible mechanisms have been applied in emissions trading. In respect to the EU ETS, for example, banking and borrowing provisions are included in the Directive 2003/87/EC. The first and second phases of the EU ETS permit allowances to be banked and borrowed within the same compliance period but prohibit banking and borrowing between different compliance periods [8]. The EU ETS issues the carbon allowance allocation plan for that year in February each year, but the performance of the previous year's allowances is submitted in April. The time difference between the two months has created conditions for the banking and borrowing of allowances [9]. Furthermore, California's LowEmission Vehicle Program allowed banking and borrowing to a certain extent for emissions of hydrocarbon. The 1990 Clean Air Act Amendments allowed companies to bank sulfur dioxide permits, and the success of the US Acid Rain Program is also due to the critical role of such provisions $[10,11]$.

The question is, when interphase banking and borrowing of allowances are both allowed, how can companies choose emission reduction policies and the auction amount of allowances to minimize the total costs? Therefore, in order to study the impact of intertemporal trading mechanisms on the company's abatement actions, based on the framework of Guo [6], in this paper, we present a stochastic control model that considers two trading periods, between which interphase banking and borrowing of permits are allowable. We call this the "inheriting period." In other words, at the end of the first phase, if the company's carbon emissions exceed the cap, the company can borrow allowances from the next phase. In contrast, if the company has remaining emission allowances, they may be used in the next phase. In addition, we use two stochastic processes to describe the evolution of carbon emissions and the price of the allowance in the market. We aimed to identify the optimal emission reduction policy and the initial auction amount in two steps, so as to minimize the total cost of the first phase. First, we fixed the initial auction amount and then minimized the cost of the emission reduction part by selecting the optimal emission reduction policy. According to the dynamic programming principle [12], the corresponding two-dimensional Hamilton-Jacobi-Bellman (HJB) equation can be obtained and it can be solved numerically by the alternating direction implicit (ADI) format. We then chose the appropriate initial allowance purchase quantity to make the total cost of the first phase the lowest. By carrying out this step, we were able to derive the implicit equation that the optimal initial auction amount satisfies. Thereafter, by referring to the numerical results, we analyze the minimum total cost and optimal policy. Finally, we present a comparison of the single-period model, the two-period model, which only allows interphase banking, and the inheriting period model, which allows interphase banking and borrowing. We conclude this paper by highlighting several policy implications after comparing the results. We expect that our model will provide a reference for governments to formulate a carbon trading compliance mechanism and for companies to carry out emission reduction actions. This also reflects the main contribution of this paper.

The remainder of the paper is organized as follows. In the next section, we review relevant literature. In Section 3, we describe the inheriting period model. In Section 4, we present the numerical calculation results of the model, analyze the minimum cost and optimal policy, and compare the three models. Section 5 concludes the paper.

\section{Literature Review}

In recent years, with the rise of the carbon finance market, many scholars have also studied relevant issues from various perspectives.

Carbon emission allowances are the foundation of the carbon trading market, so the price of allowances plays an important role in studying carbon trading behavior. Many scholars have studied the pricing of carbon allowances and their derivatives. Benz and Trück [13] discussed the shortterm dynamics of spot price for emission permits in the EU ETS. Nazifi [14] used time-varying parameter analysis to detect changes in the structural relationship between European Union Allowances (EUAs) and Certified Emission Reductions (CERs) and confirmed that the difference of rules between the project-based carbon trading market and the quota-based carbon trading market was the influencing factor of the inconsistent price fluctuations. Koop and Tole [15] found evidence of significant market turmoil and predicted the price of spot and futures in the market under the EU ETS using the Dynamic Model Average (DMA) method. Daskalakis et al. [16] analyzed the market data from Powernext, Nord Pool, and European Climate Exchange (ECX) and found that prohibiting the banking of emission allowances between distinct phases of the EU ETS had an important influence on futures pricing. They also presented 
a framework for the pricing and hedging of intraphase and interphase futures and options on futures.

In addition, some scholars focused on the optimization models of carbon emission reduction. Yang et al. [17] established a multistage mixed-integer nonlinear programming model to minimize the cost of emissions trading and green technology implementation under the cap-andtrade scheme. Yang and Liang $[18,19]$ established the minimization model of the national cost including carbon emission reduction and excess penalties by applying stochastic control theory, and they then derived the expression of the minimum cost and optimal control strategy according to the HJB equation. Guo and Liang $[20,21]$ considered carbon trading on this basis and assumed that the price of the allowance in the market satisfied geometric Brownian motion. They then derived a two-dimensional HJB equation. Rubin [11], Schennach [22], and Liski and Montero [23] studied the optimal policy of emission reduction for enterprises when emission permits can be banked during multiple trading periods.

Carbon allowance banking and borrowing are flexible trading mechanisms in the carbon emissions trading market. By studying the existing emissions trading systems, Kling and Rubin [10] and Akhurst et al. [24] found that the banking and borrowing of carbon allowances will lead to a reduction in the compliance cost due to the flexibility of intertemporal trading, which illustrates the feasibility of allowances banking and borrowing. Godby et al. [25] found that, under uncertain circumstances, the banking of carbon allowances can reduce price fluctuations, but the effect is not obvious when the market is efficient. Ehrhart et al. [26] proposed that the banking and borrowing system of carbon allowances is an effective emission reduction measure or a tool for environmental regulation.

Compared with the existing literature, the originality of this paper lies in the following aspects. First, this paper addresses an application gap by using stochastic control theories to analyze the impact of intertemporal trading on the company's emission reduction costs. In our model, we considered two trading periods and assumed that the surplus allowances in the first phase could be banked to the second phase, while the insufficient allowances could be borrowed from the second phase. Second, another feature of this paper is that previous optimization models that considered carbon emission reduction usually assumed that emission allowances were issued by the government for free. In fact, more and more studies have shown that auctioning is a more reasonable and effective allocation method [27-29]. Therefore, for companies, participating in the auctioning to obtain a reasonable amount of allowances will have an important impact on their emission reduction costs. In this study, by considering the two control factors, i.e., emission reduction policy and the initial auction amount, we developed a stochastic optimization model to minimize the total abatement cost by two steps and we transformed this problem into the task of solving a two-dimensional HJB equation. In addition, we compared the single-period model, the two-period model in the case where only interphase banking is allowed, and the inheriting period model that allows interphase banking and borrowing. We also present several policy implications by analyzing the results. This will provide a framework of reference by governments to formulate emission reduction mechanisms and for companies to reduce emissions.

\section{Modeling}

Let $(\Omega, \mathscr{F}, \mathbb{P})$ be a filtered probability space that satisfies the usual conditions, where $\mathbb{F}=\left\{\mathscr{F}_{t}, t \geq 0\right\}$ is the filtration generated by the standard Brownian motion $W_{t}$ below. In this paper, we consider a $\mathrm{CO}_{2}$-emitting company's emission reduction and allowances purchase strategies under the capand-trade program. Consider an inheriting period case, such that there are two compliance periods $[0, T]$ (Phase 1) and $\left[T, T_{1}\right]$ (Phase 2), between which interphase banking and borrowing are allowable. First, at the initial time of the performance period $t=0$, the company obtains emission allowances through free allocation by the government and auctioning in the market. It then needs to take emission reduction measures to reduce emissions. At the end of the first phase $t=T$, if the company's carbon emissions exceed the cap, the company should pay the excess penalty or borrow from the next phase. In contrast, if the company has the remaining emission allowances, they may be used in the next phase. The basic notations are listed as follows:

(i) $N_{1}$ : emission allowances issued by the government free of charge

(ii) $\mathrm{N}_{2}$ : emission allowances obtained through auction and a parameter to be determined

(iii) $S_{t}$ : the auction price of the emission allowance

(iv) $P$ : the penalty for exceeding the cap

(v) $y_{t}$ : the emissions rate of the company

(vi) $X_{t}$ : the expected cumulative emissions of the company over the first phase at time $t$

(vii) $u_{t}$ : the company's emission reduction control policy

(viii) $\bar{u}$ : the upper bound of the control policy

According to [30], suppose that the emissions rate $y_{t}$ follows

$$
\mathrm{d} y_{t}=\mu\left(t, y_{t}\right) \mathrm{d} t+\sigma\left(t, y_{t}\right) \mathrm{d} W_{t},
$$

where $\mu\left(t, y_{t}\right)$ and $\sigma\left(t, y_{t}\right)$ express the deterministic drift and volatility, respectively, and $W_{t}$ is the $\mathscr{F}_{t}$-adapted standard Brownian motion.

Considering carbon reduction, we can deduce that the expected cumulative emissions $X_{t}$ over the first phase $[0, T]$ satisfy

$$
X_{t}=-\int_{0}^{t} u_{s} \mathrm{~d} s+E\left[\int_{0}^{T} y_{s} \mathrm{~d} s \mid \mathscr{F}_{t}\right]
$$

where $u_{t}$ is the abatement control policy, representing instantaneous abatement rate. Let us assume that $u_{t}$ is an $\left\{\mathscr{F}_{t}\right\}_{t \geq 0}$-adapted process and satisfies $0 \leq u_{t} \leq \bar{u}$, while $\bar{u}$ is a 
constant and represents the maximum capacity for carbon reduction. The set of all admissible controls is denoted by $\mathcal{U}$.

That is, $X_{t}$ considers both known emissions and abatement actions before time $t$ and the expected future emissions from $t$ to $T$. Therefore, $X_{T}$ represents the actual cumulative emissions with abatement action during $[0, T]$ at the end of first phase. Then, according to equation (2), we have

$$
\mathrm{d} X_{t}=-u_{t} \mathrm{~d} t+G(t) \mathrm{d} W_{t},
$$

where $G(t)$ is the volatility and it is determined by $\mu\left(t, y_{t}\right)$ and $\sigma\left(t, y_{t}\right)$. For the derivation of $G(t)$, see [30] for further details.
Suppose that the auction price of the emission allowance $S_{t}$ in the market satisfies the following geometric Brownian motion:

$$
\mathrm{d} S_{t}=\mu S_{t} \mathrm{~d} t+\sigma S_{t} \mathrm{~d} W_{t}^{2}
$$

A similar assumption can be found in $[20,21]$, where $\mu$ and $\sigma$ represent constant drift and volatility, respectively, while $W_{t}^{2}$ is the $\mathscr{F}_{t}$-adapted standard Brownian motion. Let us also assume that $\operatorname{corr}\left(\mathrm{d} W_{t}, \mathrm{~d} W_{t}^{2}\right)=0$.

Therefore, the present value of the total cost of emission reduction of the first phase $[0, T]$ at $t=0$ satisfies

$$
E\left[\int_{0}^{T} e^{-r \xi} C\left(u_{\xi}\right) d \xi+e^{-r T} \min \left\{P, S_{T}\right\}\left(X_{T}-N_{1}-N_{2}\right)^{+}-e^{-r T} S_{T}\left(X_{T}-N_{1}-N_{2}\right)^{-}+S_{0} N_{2}\right] .
$$

The aim of the company is to minimize the above formula, and it contains four partial cash flows. The first part is the cost of adopting emission reduction technology in the first phase $[0, T]$, where $r$ is the risk-free interest rate, $C\left(u_{\xi}\right)=(1 / 2) m u_{\xi}^{2}$ represents the consumption function describing abatement costs per unit of time, where $m$ is a positive constant, such that the larger the value, the lower the emission reduction efficiency (similar assumption, see also $[20,21,30])$; the second part indicates that if the cumulative emissions $X_{T}$ at time $T$ exceed the cap $N_{1}+N_{2}$, the company chooses to pay the penalty or borrow allowances from the next phase. If the auction price of the emission allowance $S_{T}$ at time $T$ is lower than the penalty $P$, then the company chooses interphase borrowing. In this case, the company needs to repay the borrowed allowances through auctions at the beginning of the second phase, thus costing $S_{T}\left(X_{T}-N_{1}-N_{2}\right)^{+}$; the third part is the value of the remaining emission allowances. In fact, if the cumulative emissions at time $T$ do not exceed the cap $N_{1}+N_{2}$, interphase banking can be performed, i.e., the remaining emission allowances are valuable and can be used for the next phase. Since the company still needs to obtain allowances through auctions at the initial time of the second phase, the value of the remaining allowances in the previous phase is equal to $S_{T}\left(X_{T}-N_{1}-N_{2}\right)^{-}$; the fourth part is the cost of buying allowances through auctions at the initial time $t=0$ of the first phase.

For this problem, we optimize in two steps. First, fix $N_{2}$ and choose the optimal emission reduction control policy $u^{*}$ to minimize the cost of emission reduction of the first phase, and then choose the reasonable initial auction amount of allowances $N_{2}^{*}$ to make the total cost of the first phase the lowest.

It can be seen from equation (5) that the minimum emission reduction cost of the first phase $[0, T]$ (excluding the cost of auction) satisfies

$$
\begin{aligned}
V\left(x, s, t ; N_{2}\right)= & \inf _{0 \leq u \leq \bar{u}} E\left[\int_{t}^{T} e^{-r(\xi-t)} C\left(u_{\xi}\right) \mathrm{d} \xi+e^{-r(T-t)} \min \left\{P, S_{T}\right\}\left(X_{T}-N_{1}-N_{2}\right)^{+}\right. \\
& \left.-e^{-r(T-t)} S_{T}\left(X_{T}-N_{1}-N_{2}\right)^{-} \mid X_{t}=x, S_{t}=s\right] .
\end{aligned}
$$

According to the dynamic programming principle [12], the corresponding HJB equation is expressed as follows:

$$
\inf _{0 \leq u \leq \bar{u}}\left[\frac{\partial V}{\partial t}-u \frac{\partial V}{\partial x}+\mu s \frac{\partial V}{\partial s}+\frac{1}{2} G^{2}(t) \frac{\partial^{2} V}{\partial x^{2}}+\frac{1}{2} \sigma^{2} s^{2} \frac{\partial^{2} V}{\partial s^{2}}+\frac{1}{2} m u^{2}-r V\right]=0, \quad(x, s, t) \in R \times R^{+} \times[0, T)
$$

The terminal condition is

$$
V\left(x, s, T ; N_{2}\right)=\min \{P, s\}\left(x-N_{1}-N_{2}\right)^{+}-s\left(x-N_{1}-N_{2}\right)^{-}, \quad x \in R, s \in R^{+} .
$$


Since the emission reduction control policy $u$ is bounded and satisfies $0 \leq u \leq \bar{u}$, the optimal emission reduction policy can be expressed as

$$
u^{*}= \begin{cases}0, & \frac{\partial V}{\partial x}<0 \\ \frac{1}{m} \frac{\partial V}{\partial x}, & 0 \leq \frac{\partial V}{\partial x} \leq m \bar{u} \\ \bar{u}, & \frac{\partial V}{\partial x}>m \bar{u} .\end{cases}
$$
as

When $0 \leq(\partial V / \partial x) \leq m \bar{u}$, equation (7) can be expressed

$$
\frac{\partial V}{\partial t}-\frac{1}{2 m}\left(\frac{\partial V}{\partial x}\right)^{2}+\mu s \frac{\partial V}{\partial s}+\frac{1}{2} G^{2}(t) \frac{\partial^{2} V}{\partial x^{2}}+\frac{1}{2} \sigma^{2} s^{2} \frac{\partial^{2} V}{\partial s^{2}}-r V=0 .
$$

Equation (10) is a two-dimensional nonlinear partial differential equation. In general, it is difficult to obtain an expression for its analytical solution. Thus, we solve it by means of numerical methods.

Since the total cost of the first phase satisfies

$$
V_{\text {cost }}=V\left(x, S_{0}, 0 ; N_{2}\right)+S_{0} N_{2},
$$

then in order to minimize the total cost, when the initial expected emissions $X_{0}$ and the initial auction price $S_{0}$ are given, the reasonable initial purchase amount $N_{2}^{*}$ should satisfy

$$
\left.\frac{\partial V\left(X_{0}, S_{0}, 0 ; N_{2}\right)}{\partial N_{2}}\right|_{N_{2}=N_{2}^{*}}+S_{0}=0 .
$$

\section{Numerical Results}

In this section, we use the ADI format to produce the numerical results of the above HJB equation (10). We then analyze the properties of minimum cost and optimal policy. For convenience, suppose that $G(t) \equiv \sigma_{1}$ is a constant. The values of parameters are shown in Table 1.

Figure 1 illustrates the relationship between the emission reduction cost $V_{0}$ (excluding the cost of auction), initial expected cumulative emissions $X_{0}$, and the initial auction price $S_{0}$. As can be seen from the figure, as $X_{0}$ increases, the emission reduction cost $V_{0}$ will increase monotonously. This is because, in this case, the intensity of the subsequent emission reduction will increase.

In addition, when $X_{0}$ is lower and the initial auction price $S_{0}$ is higher, the emission reduction cost $V_{0}$ will be less. Obviously, the probability of surplus emission allowances is higher at the end of the first phase in this case, and because the banking of allowances is allowed, the value of the surplus allowances is higher when $S_{0}$ is higher.

Furthermore, at the end of the first phase, the probability of excess emissions will increase as $X_{0}$ increases. Because emission allowances may be borrowed from the next phase, when the auction price is higher, the auction cost at the
TABLE 1: Values of parameters.

\begin{tabular}{lccccccccc}
\hline $\mathrm{P}(€ /$ ton $)$ & $\begin{array}{c}N_{1} \\
\text { (ton) }\end{array}$ & $\begin{array}{c}N_{2} \\
\text { (ton) }\end{array}$ & $\sigma$ & $\sigma_{1}$ & $\mu$ & $m$ & $\mathrm{~T}$ (year) & $r$ \\
\hline 100 & 1000 & 4000 & 0.2 & 150 & 0.02 & 0.2 & 1 & 0.04 \\
\hline
\end{tabular}

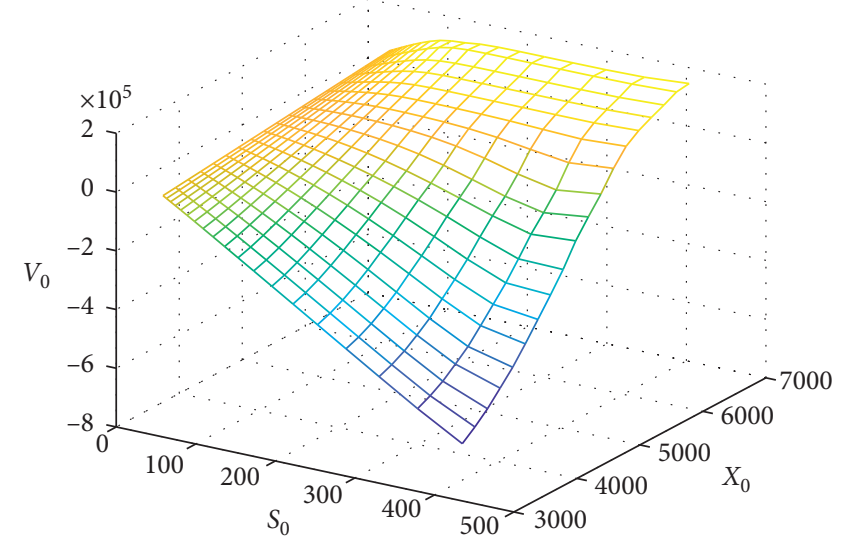

FIgURE 1: Relationship between $V_{0}, X_{0}$, and $S_{0}$.

initial time of the second phase will be more, so the emission reduction cost $V_{0}$ will be higher. However, when the initial auction price $S_{0}$ reaches a certain value, the emission reduction cost does not change with the initial auction price. It is easy to understand: in this case, the penalty is lower than the auction price, so the company will choose to pay the penalty for excess emissions.

4.1. Minimum Cost Analysis. At the initial time $t=0$, the minimum total cost of reducing emissions can be expressed as follows:

$$
V_{\text {cost }}=V\left(x, S_{0}, 0 ; N_{2}^{*}\right)+S_{0} N_{2}^{*} .
$$

Figure 2 shows the relationship between the minimum total cost of reducing emissions and the company's initial expected cumulative emissions $X_{0}$. It can be seen from the figure that, under the same conditions, $X_{0}$ is more, and the minimum total cost is higher, because the company is faced with a larger emission reduction task at this time.

Figure 3 illustrates the relationship between the minimum total cost of reducing emissions and the emission reduction efficiency parameter $m$. The larger the value of $m$, the lower the emission reduction efficiency. As can be seen from the figure, if companies improve the efficiency of emission reduction, the cost of emission reduction will decrease.

Figure 4 shows the relationship between the minimum total cost of reducing emissions and the excess penalty. Under the same conditions, as the penalty $P$ increases, the minimum total cost $V_{\text {cost }}$ will also increase. When the penalty exceeds a certain value, $V_{\text {cost }}$ basically remains the same as $P$ increases. This is because, in this case, the auction price at $t=T$ is lower than the penalty. Therefore, in order to minimize the cost, the company will choose the borrowing of allowances. 


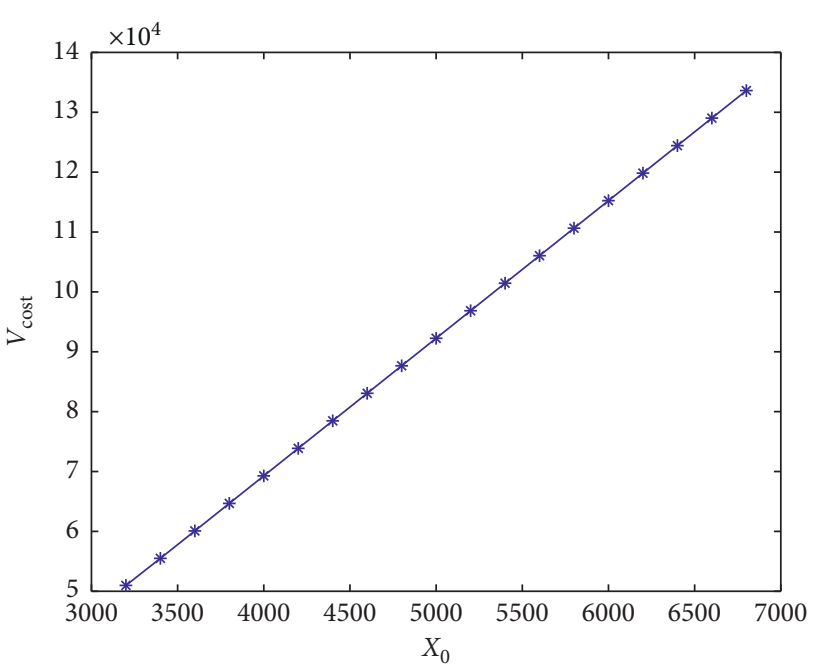

Figure 2: The relationship between $V_{\text {cost }}$ and $X_{0}$.

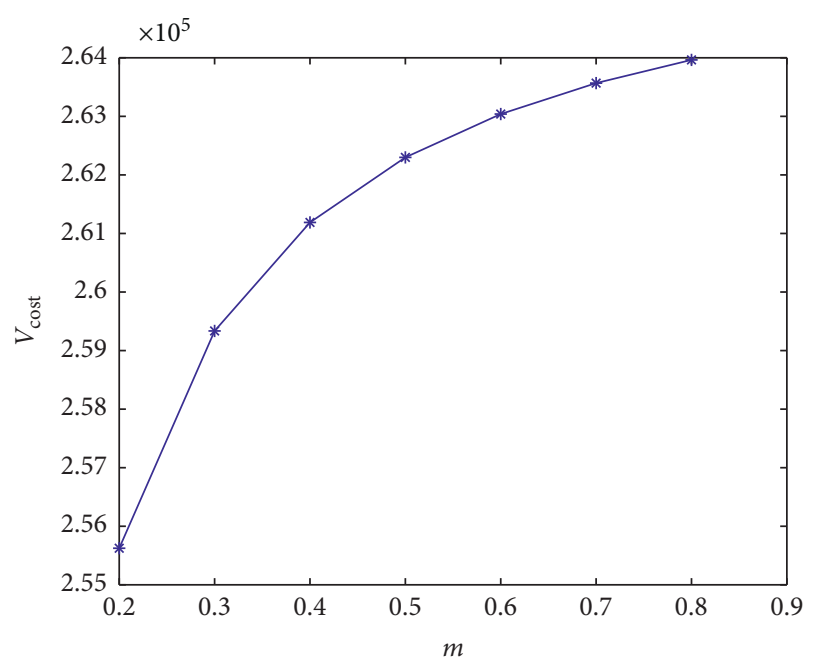

Figure 3: The relationship between $V_{\text {cost }}$ and $m$.

Figures 5 and 6 show that, under the same conditions, the total cost of emission reduction decreases as the volatility, $\sigma_{1}$ and $\sigma$, increases.

4.2. Optimal Policy Analysis. Figure 7 shows the relationship between the optimal emission reduction policy, initial expected cumulative emissions $X_{0}$, and the initial auction price of the allowance $S_{0}$. As shown in the figure, the optimal policy curve increases with the increase in the initial auction price. That is, as $S_{0}$ increases, in order to minimize the cost of emission reduction, the company should increase its emission reduction efforts. In fact, if the initial emission auction price is higher, the probability of a higher auction price at time $T$ will also be greater. Furthermore, if the emissions exceed the cap at time $T$, due to interphase borrowing of allowances, the auction cost of the company at the initial time $T$ of the second phase will be higher. However, if the emissions do not exceed the limit, the value of surplus allowances is higher because of interphase

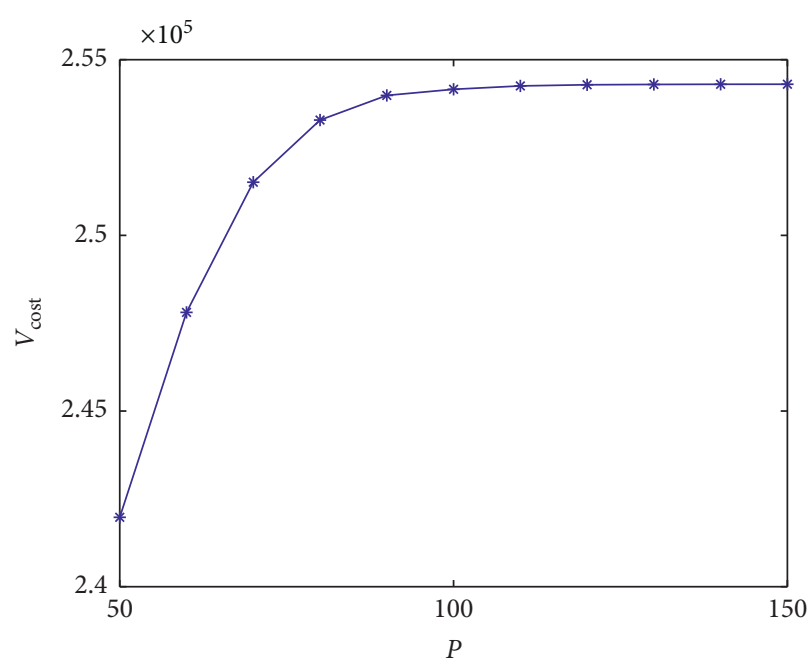

FIgURE 4: The relationship between $V_{\text {cost }}$ and $P$.

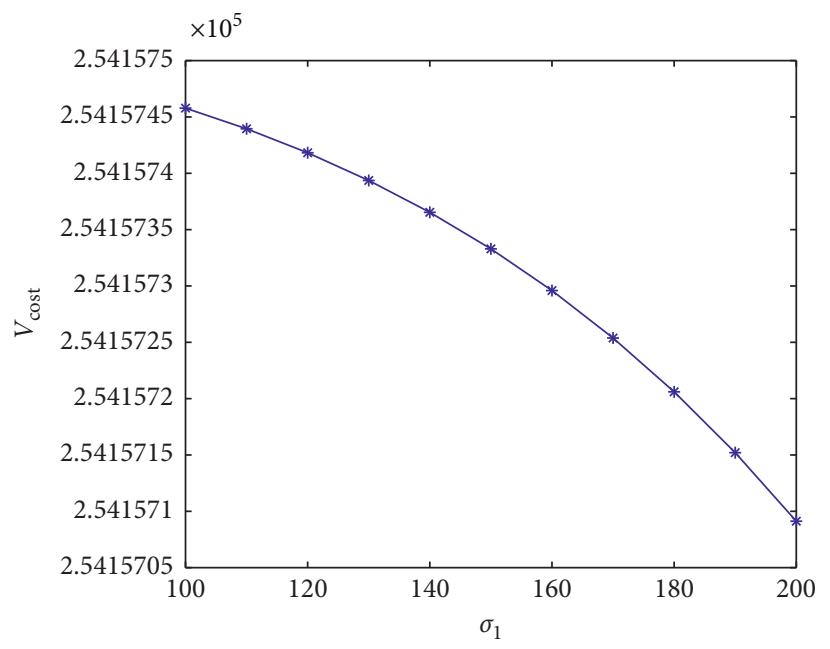

Figure 5: The relationship between $V_{\text {cost }}$ and $\sigma_{1}$.

banking. Therefore, as $S_{0}$ increases, companies should increase their emission reduction efforts so that the emissions are lower at time $T$.

In addition, as the initial expected cumulative emissions $X_{0}$ increase, the optimal policy will increase. In fact, when the initial expected cumulative emissions are higher, the company needs to intensify its emission reduction efforts at the beginning.

4.3. Model Comparison. Let $V_{1}$ be the minimum emission reduction cost (excluding the cost of auction) for the singleperiod model (Model 1) in [6], and let $V_{2}$ be the minimum emission reduction cost (excluding the cost of auction) for the two-period model (Model 2) wherein only interphase banking of emission allowances is allowable [6]. $V_{3}$ is the minimum emission reduction cost (excluding the cost of auction) for the inheriting period model (Model 3), which, in this paper, allows interphase banking and borrowing of emission allowances. 
According to Guo's work [6], $V_{1}$ satisfies

$$
V_{1}\left(x, t ; N_{2}\right)=\inf _{u \in[0, \bar{u}]} E\left[\int_{t}^{T} e^{-r(s-t)} C\left(u_{s}\right) \mathrm{d} s+e^{-r(T-t)} P\left(X_{T}-N_{1}-N_{2}\right)^{+} \mid X_{t}=x\right] .
$$

Then, the corresponding HJB equation satisfies

$$
\inf _{0 \leq u \leq \bar{u}}\left[\frac{\partial V_{1}}{\partial t}-u \frac{\partial V_{1}}{\partial x}+\frac{1}{2} G^{2}(t) \frac{\partial^{2} V_{1}}{\partial x^{2}}+\frac{1}{2} m u^{2}-r V_{1}\right]=0, \quad(x, t) \in R \times[0, T) .
$$

The terminal condition satisfies

$$
V_{1}\left(x, T ; N_{2}\right)=P\left(x-N_{1}-N_{2}\right)^{+}, \quad x \in R .
$$

In addition, $V_{2}$ satisfies

$$
\begin{aligned}
V_{2}\left(x, s, t ; N_{2}\right)= & \inf _{0 \leq u \leq \bar{u}} E\left[\int_{t}^{T} e^{-r(\xi-t)} C\left(u_{\xi}\right) \mathrm{d} \xi+e^{-r(T-t)} P\left(X_{T}-N_{1}-N_{2}\right)^{+}\right. \\
& \left.-e^{-r(T-t)} S_{T}\left(X_{T}-N_{1}-N_{2}\right)^{-} \mid X_{t}=x, S_{t}=s\right] .
\end{aligned}
$$

Thus, its corresponding HJB equation is

$$
\inf _{0 \leq u \leq \bar{u}}\left[\frac{\partial V_{2}}{\partial t}-u \frac{\partial V_{2}}{\partial x}+\mu s \frac{\partial V_{2}}{\partial s}+\frac{1}{2} G^{2}(t) \frac{\partial^{2} V_{2}}{\partial x^{2}}+\frac{1}{2} \sigma^{2} s^{2} \frac{\partial^{2} V_{2}}{\partial s^{2}}+\frac{1}{2} m u^{2}-r V_{2}\right]=0, \quad(x, s, t) \in R \times R^{+} \times[0, T)
$$

The terminal condition is

$$
V_{2}\left(x, s, T ; N_{2}\right)=P\left(x-N_{1}-N_{2}\right)^{+}-s\left(x-N_{1}-N_{2}\right)^{-}, \quad x \in R, s \in R^{+} .
$$

The meaning of each parameter in the above equations is the same as that in the inheriting period model. Below, we compare the above three models using numerical analysis.

Figure 8 shows the relationship between the emission reduction cost and the initial expected emissions $X_{0}$ in the three models. Under the same conditions, as $X_{0}$ increases, the emission reduction cost in the three scenarios grows higher and higher, and the cost of the inheriting period model, which allows interphase banking and borrowing of allowances, is the lowest in the three models. In fact, when $X_{0}$ is higher, the probability of the company's emissions exceeding the limit is greater in this case. Since the cost of interphase borrowing is less than the excess penalty, the cost of the inheriting period model will be the lowest. In this case, the emission reduction costs are roughly the same between the singleperiod model and the two-period model that only allows the interphase banking of allowances, since at this time they can only choose to accept the penalty when the company's emissions exceed the limit. In addition, when $X_{0}$ is lower, there is a high probability of remaining allowances at this time, so that the allowances can be banked to the second phase in the two two-period models. Therefore, the emission reduction costs of the two models are basically the same and they are lower than the cost of the single-period model.

Figure 9 shows the relationship between the emission reduction cost and the initial allowances purchase amount $N_{2}$ in the three models. That is to say, under the same conditions, the more purchases that are obtained through auctions at the initial time, the lower the cost of subsequent emission reductions. However, in this scenario, the expenses that are required for the auctions are higher, so in order to minimize the total cost, companies can determine the best purchase amount by examining the relationship between the declining rate of $V$ relative to $N_{2}$ and the initial auction price $S_{0}$.

In addition, as can be seen from the figure, the cost of the inheriting period model that allows interphase banking and borrowing of allowances is the lowest in the three models. In fact, when $N_{2}$ is lower, there is a high probability that a company will exceed its emissions limit. Since the cost of interphase borrowing is less than the excess penalty, the cost of the inheriting period will be the lowest. In this case, the emission reduction costs are roughly the same between the single-period model and the two-period model that only allows the interphase banking of allowances, since at this time they can only choose to accept the penalty. When the initial purchase amount $N_{2}$ is higher, the single-period model has the highest emission reduction cost, because the probability of surplus allowances is high in this case, and the two two-period models allow interphase banking of the emission allowances. Therefore, at the initial time of the second phase, the surplus allowances are valuable, so the costs of the two two-period models are roughly the same and they are both lower than the cost of the single-period model. 


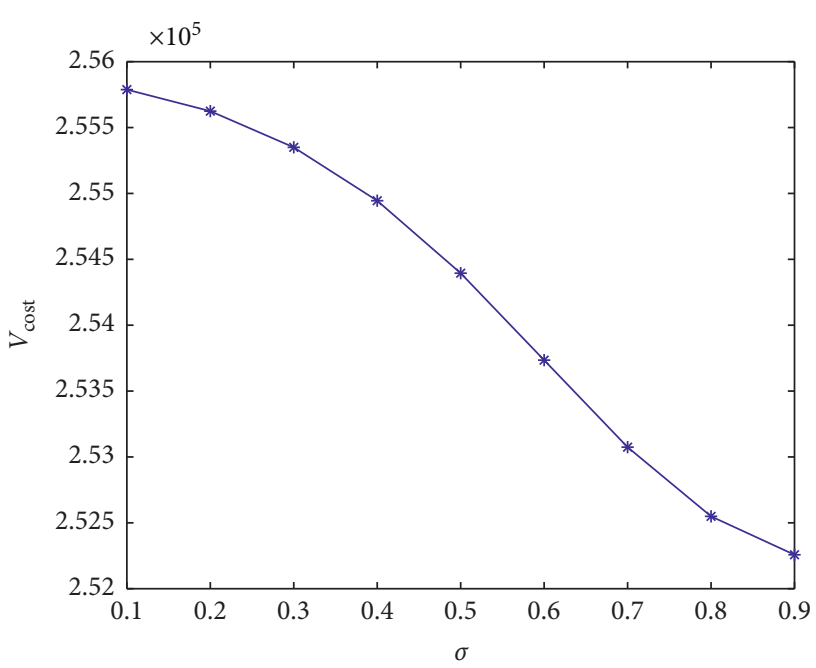

FIgURE 6: The relationship between $V_{\text {cost }}$ and $\sigma$.

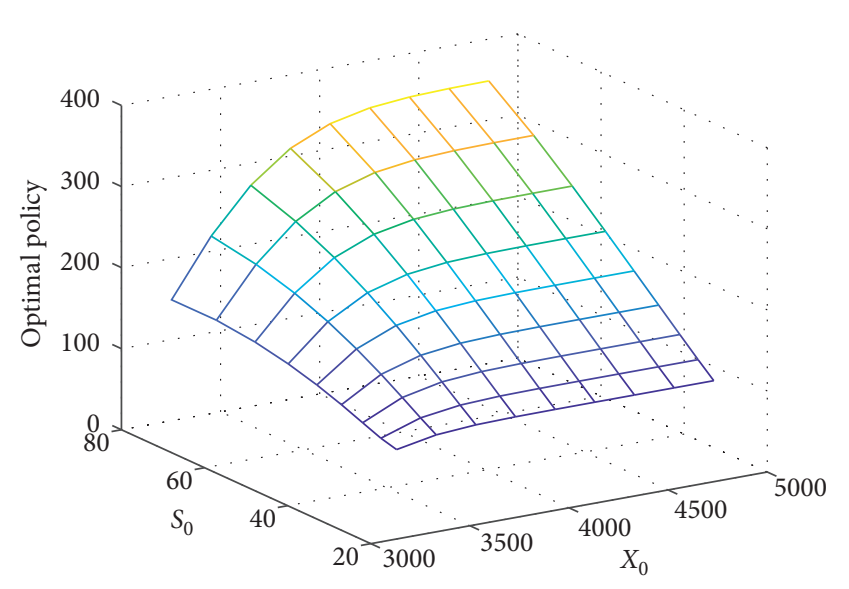

Figure 7: Optimal policy, $X_{0}$, and $S_{0}$.

Since governments aim to reduce emissions, we compare the emission reductions in the three models and the results are presented in Figure 10. According to the evolution process of the expected cumulative emissions in equation (3), we can deduce that the optimal expected emission reduction of the first phase is equal to $\int_{0}^{T} u_{t}^{*} \mathrm{~d} t$. Figure 10 shows that, as the penalty per unit increases, the emission reductions of the three models also increase. This can be easily understood because, in order to avoid excessive penalties, the company should continue to increase its emission reduction efforts. Moreover, it can be seen from Figure 10 that when the penalty is lower, the expected emission reductions in the three models are the same. In fact, in this case, the auction price of allowances at the end of the first phase is higher than the penalty, so even if interphase borrowing is allowed in the inheriting model, it will not be implemented. Therefore, the emission reductions of the three models are the same. However, when the penalty increases to a certain value, the emission reductions in the inheriting model will remain unchanged, because in this case the auction price is lower than the penalty, and the company will choose to borrow the emission allowances from the next phase.
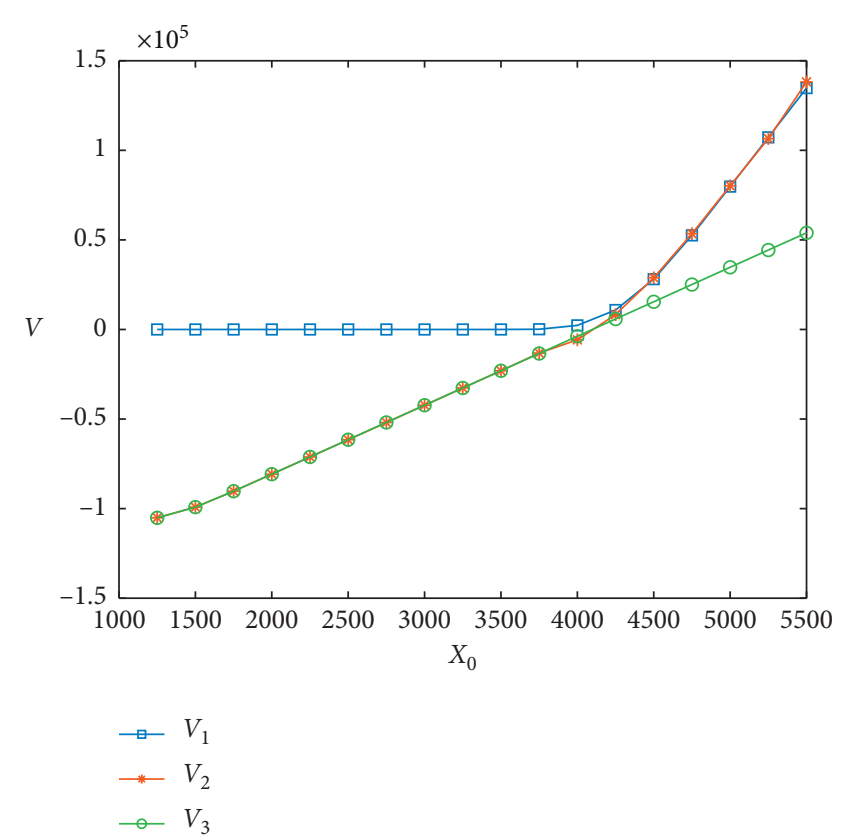

FIgURE 8: The relationship between the emission reduction cost and the initial expected emissions $X_{0}$ in the three models.

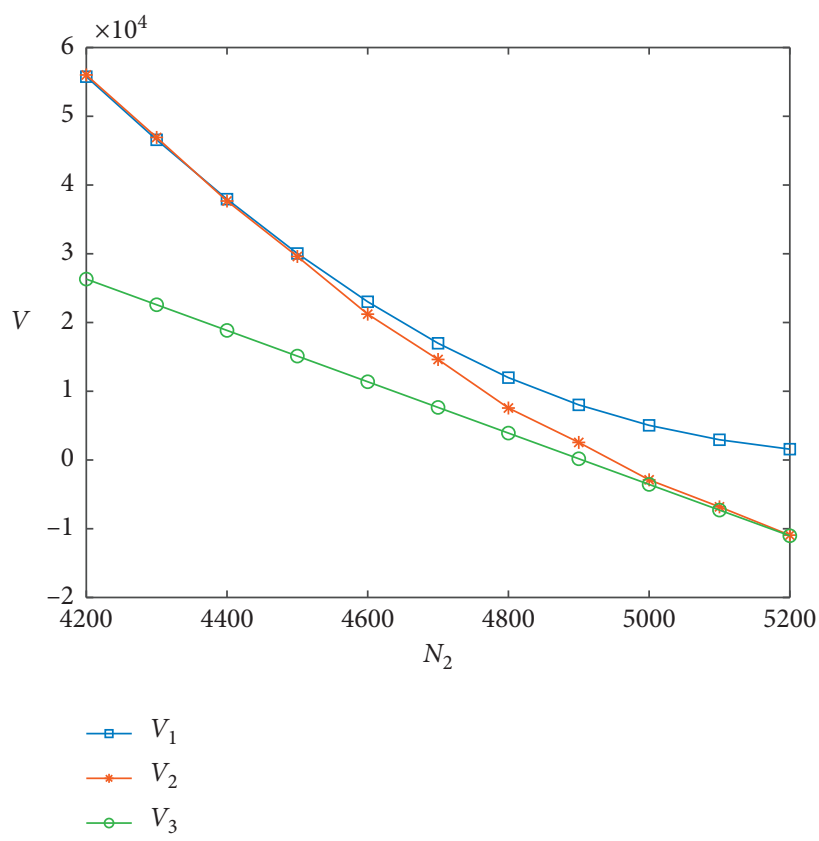

FIgURE 9: The relationship between the emission reduction cost and the initial auction amount $N_{2}$ in the three models.

4.4. Summing Up. From the above numerical analysis and comparison, several observations can be summarized as follows:

First, in the inheriting model, as the initial expected cumulative emissions increase, the emission reduction costs will become higher and higher, because, regardless of whether the company subsequently accepts excess penalties or borrows allowances from the second phase, it will have to spend more. In addition, with initial auction 


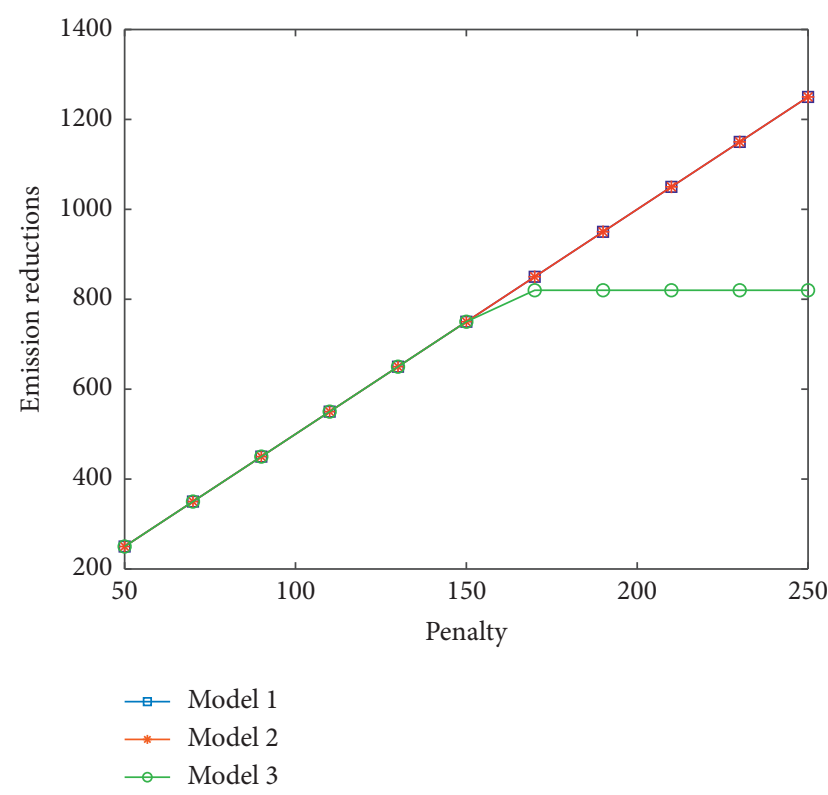

FIGURE 10: The relationship between the emission reductions and the penalty in three models.

price increases, companies should increase their emission reduction efforts, and since interphase banking and borrowing of allowances are allowed in our model, the company can save more costs by doing so. Moreover, the company should compare the marginal abatement cost with the penalty and the auction price at time $T$ when reducing emissions, so as to make reasonable emission reduction policies.

Second, the above results indicate that the minimum total cost is an increasing function of the initial emissions. Furthermore, the auction price of allowances, the company's emission reduction capability and efficiency, the penalty, and the uncertainty surrounding expected emissions and the auction price all have a significant impact on emission reduction policy and emission reduction costs. Therefore, when companies formulate emission reduction strategies and governments allocate emission reduction tasks, they should consider the actual situation of each company.

Finally, it can be seen from the comparison results that intertemporal trading can reduce the company's performance costs due to its flexibility. However, in terms of emission reductions, and since allowance borrowing provides companies with more options, they will reduce their own emission reductions. In addition, for the government, increasing the excess penalty appropriately provides an incentive for companies to reduce emissions.

\section{Concluding Remarks}

In this paper, we developed a stochastic control model to discuss the optimal auction amounts of allowances and abatement policy for companies. In our model, we considered two compliance periods, between which interphase banking and borrowing of allowances are allowed. We then identified a two-step optimization method to solve this problem. Through the first step of optimization, we obtained a HJB equation and solved it numerically using a finite difference method. In the second step, we obtained an implicit equation satisfied by the optimal purchase amount. We also analyzed the minimum total cost and optimal policy by referring to numerical results. Finally, we compared the single-period model with the two-period models in two different scenarios.

From our results, we highlight the following policy implications:

First, companies should pay attention to the auction price of the allowance and adjust their emission reduction efforts. They should then examine the relationship between the rate of decline of the emission reduction cost relative to the auction amount and the current auction price of the allowance, so as to determine the optimal auction amount. On the other hand, companies usually have an estimate of their own carbon emissions. If the auction amount is determined in advance, the company can also obtain a reasonable expected auction price for allowances through an implicit equation satisfied by the optimal auction amount and the initial auction price. In addition, when the government conducts the auction of allowances, it usually sets an auction reserve price. If the last auction price is lower than the reserved price, the auction will be cancelled. This arrangement seeks to protect the emission rights market and enable bidders to purchase allowances at a reasonable price. The government can calculate it based on the expected emission reductions of this phase before the auction. That is, under this price setting, the company has the lowest cost through emission reductions and auctions. If the reserve price is set too high, it will easily be higher than the auction price and the auction will be cancelled; if it is set too low, it will not help to encourage participants to actively reduce emissions.

Second, in the process of reducing emissions, companies should comprehensively consider their own emission reduction efficiency, the auction price of the allowance, and the penalty, while also making reasonable decisions in these respects, in order to achieve their emission reduction tasks more economically. Furthermore, from a long-term perspective, the introduction of more efficient emission reduction technologies will help to reduce the total cost of emission reduction. In addition, when formulating the emission reduction tasks of each company, the government should refer to the initial expected emissions of the company and allocate fair allowances for each company, so as to attract more emission reduction participants.

Furthermore, banking and borrowing mechanisms increase the flexibility of carbon allowances in the time dimension and enable companies to implement interperiod management of carbon assets, so as to reduce emission reduction costs of companies. Moreover, companies can formulate different emission reduction strategies based on changes of the allowances price in different time periods. For example, when a company predicts that the carbon price will rise in the future, it can purchase a large amount 
of carbon allowances in the current phase and bank them for future use; and when the carbon price is expected to fall down in the future, it can reduce the auction amount in the current phase and borrow the allowances from the next phase. Compared with the single-period case, although the banking mechanism motivates companies to take early emission reduction actions, unlimited borrowing may exacerbate environmental hazards in the short term. Nonetheless, the government may compensate for this potential harm by implementing a specific discount rate on borrowing $[8,10]$.

This study still has limitations and further research is needed. In our model, the goal was to minimize the company's total costs. However, the lowest cost is not usually the optimal choice. For example, the emission reduction policy of the company will affect many factors, such as production and profit. Therefore, in further research, the reasonable utility function, which describes the comprehensive effect of emission reduction, can be regarded as replacing the goal of the lowest total cost. In addition, in this paper, the auction is assumed to be concentrated at a specific time point within a compliance period, while the actual trading time is usually not fixed, and it is possible for companies to participate in the auction of allowances at multiple time points. Therefore, further research can consider an optimization model with multiple auction time points within a compliance period. In this way, multiple control variables will be generated in the optimal control model.

\section{Data Availability}

The data used to support the findings of this study are available from the corresponding author upon request.

\section{Conflicts of Interest}

The authors declare that they have no conflicts of interest.

\section{Acknowledgments}

This work was supported by the National Natural Science Foundation of China (Grant no. 11671301 and 12071349).

\section{References}

[1] ICAP, Emissions Trading Worldwide: Status Report 2019, 2019, https://icapcarbonaction.com/ru/icap-status-report-2019.

[2] European Commission, The EU Emissions Trading System (EU ETS), 2013, http://ec.europa.eu/clima/publications/docs/ factsheet_ets_en.pdf.

[3] B. Ye, "EU-ETS 3-phase quota distribution and its evolution," China Opening Journal, vol. 3, pp. 64-68, 2013.

[4] J. K. Goeree, K. Palmer, C. A. Holt, W. Shobe, and D. Burtraw, "An experimental study of auctions versus grandfathering to assign pollution permits," Journal of the European Economic Association, vol. 8, no. 2-3, pp. 514-525, 2011.

[5] L. Liu, X. Sun, C. Chen, and E. Zhao, "How will auctioning impact on the carbon emission abatement cost of electric power generation sector in China?" Applied Energy, vol. 168, pp. 594-609, 2016.
[6] H. Guo, Research on stochastic optimization model related to carbon emission reduction and carbon trade, Ph.D.thesis, Tongji University, Shanghai, China, 2018.

[7] J. Schleich, K.-M. Ehrhart, C. Hoppe, and S. Seifert, "Banning banking in EU emissions trading?" Energy Policy, vol. 34, no. 1, pp. 112-120, 2006.

[8] J. Chevallier, "Banking and borrowing in the EU ETS: a review of economic modelling, current provisions and prospects for future design," Journal of Economic Surveys, vol. 26, no. 1, pp. 157-176, 2012.

[9] J. Wang, "Research of carbon emissions quota banking and borrowing," Master thesis, University of Jinan, 2016.

[10] C. Kling and J. Rubin, "Bankable permits for the control of environmental pollution," Journal of Public Economics, vol. 64, no. 1, pp. 101-115, 1997.

[11] J. D. Rubin, "A model of intertemporal emission trading, banking, and borrowing," Journal of Environmental Economics and Management, vol. 31, no. 3, pp. 269-286, 1996.

[12] H. Pham, Continuous-time Stochastic Control and Optimization with Financial Applications, Springer, Berlin, Heidelberg, 2009.

[13] E. Benz and S. Trück, "Modeling the price dynamics of $\mathrm{CO}_{2}$ emission allowances," Energy Economics, vol. 31, no. 1, pp. 4-15, 2009.

[14] F. Nazifi, "Modelling the price spread between EUA and CER carbon prices," Energy Policy, vol. 56, pp. 434-445, 2013.

[15] G. Koop and L. Tole, "Forecasting the European carbon market," Journal of the Royal Statistical Society: Series A (Statistics in Society), vol. 176, no. 3, pp. 723-741, 2013.

[16] G. Daskalakis, D. Psychoyios, and R. N. Markellos, "Modeling $\mathrm{CO}_{2}$ emission allowance prices and derivatives: evidence from the European trading scheme," Journal of Banking \& Finance, vol. 33, no. 7, pp. 1230-1241, 2009.

[17] W. Yang, Y. Pan, J. Ma, M. Zhou, Z. Chen, and W. Zhu, "Optimization on emission permit trading and green technology implementation under cap-and-trade scheme," Journal of Cleaner Production, vol. 194, no. 1, pp. 288-299, 2018.

[18] X. Yang and J. Liang, "Minimization of the nation cost due to carbon emission," Systems Engineering-Theory \& Practice, vol. 34, no. 3, pp. 640-647, 2014.

[19] X. Yang, J. Liang, and B. Hu, "Minimization of carbon abatement cost: modeling, analysis and simulation," Discrete and Continuous Dynamical Systems Series B, vol. 22, no. 7, pp. 2939-2969, 2017.

[20] H. Guo and J. Liang, "An optimal control model for reducing and trading of carbon emissions," Physica A: Statistical Mechanics and Its Applications, vol. 446, no. 15, pp. 11-21, 2016.

[21] H. Guo and J. Liang, "An optimal control model of carbon reduction and trading," Mathematical Control and Related Fields, vol. 6, no. 4, pp. 535-550, 2016.

[22] S. M. Schennach, "The economics of pollution permit banking in the context of title IV of the 1990 clean Air Act Amendments," Journal of Environmental Economics and Management, vol. 40, no. 3, pp. 189-210, 2000.

[23] M. Liski and J.-P. Montero, "A note on market power in an emission permits market with banking," Environmental and Resource Economics, vol. 31, no. 2, pp. 159-173, 2005.

[24] M. Akhurst, J. Morgheim, and R. Lewis, "Greenhouse gas emissions trading in BP," Energy Policy, vol. 31, no. 7, pp. 657-663, 2003.

[25] R. W. Godby, S. Mestelman, R. A. Muller, and J. D. Welland, "Emissions trading with shares and coupons when control over discharges is uncertain," Journal of Environmental Economics and Management, vol. 32, no. 3, pp. 359-381, 1997. 
[26] K.-M. Ehrhart, C. Hoppe, and R. Löschel, "Abuse of EU emissions trading for tacit collusion," Environmental and Resource Economics, vol. 41, no. 3, pp. 347-361, 2008.

[27] D. Burtraw and K. McCormack, "Consignment auctions of free emissions allowances," Energy Policy, vol. 107, pp. 337344, 2017.

[28] B. Liu, P. He, B. Zhang, and J. Bi, "Impacts of alternative allowance allocation methods under a cap-and-trade program in power sector," Energy Policy, vol. 47, pp. 405-415, 2012.

[29] Y.-B. Lai, "Auctions or grandfathering: the political economy of tradable emission permits," Public Choice, vol. 136, no. 1-2, pp. 181-200, 2008.

[30] J. Seifert, M. Uhrig-Homburg, and M. Wagner, "Dynamic behavior of $\mathrm{CO}_{2}$ spot prices," Journal of Environmental Economics and Management, vol. 56, no. 2, pp. 180-194, 2008. 